\title{
Tyrosine Hydroxylase Replacement in Experimental Parkinson's Disease with Transvascular Gene Therapy
}

\author{
William M. Pardridge \\ Department of Medicine, UCLA, Los Angeles, California 90024
}

\begin{abstract}
Summary: Transvascular gene therapy of Parkinson's disease $(\mathrm{PD})$ is a new approach to the gene therapy of PD and involves the global distribution of a therapeutic gene to brain after an intravenous administration and transport across the blood-brain barrier (BBB). This is enabled with the development of a nonviral gene transfer technology that encapsulates plasmid DNA inside pegylated immunoliposomes or PILs. An 85- to 100-nm liposome carries the DNA inside the nanocontainer, and the liposome surface is conjugated with several thousand strands of 2000-Da polyethyleneglycol (PEG). This PEGylation of the liposome stabilizes the structure in the blood stream. The liposome is targeted across the $\mathrm{BBB}$ via attachment to the tips of $1-2 \%$ of the PEG strands of a receptor-specific monoclonal antibody $(\mathrm{mAb})$ directed at a $\mathrm{BBB}$ receptor, such as the insulin receptor or transferrin receptor (TfR). Owing to the
\end{abstract}

expression of the insulin receptor or the TfR on both the BBB and the neuronal plasma membrane, the PIL is able to reach the neuronal nuclear compartment from the circulation. Brain-specific expression is possible with the combined use of the PIL gene transfer technology and brain-specific gene promoters. In the 6-hydroxydopamine rat model of experimental PD, striatal tyrosine hydroxylase (TH) activity is completely normalized after an intravenous administration of TfRmAb-targeted PILs carrying a TH expression plasmid. A treatment for PD may be possible with dual gene therapy that seeks both to replace striatal TH gene expression with TH gene therapy, and to halt or reverse neurodegeneration of the nigro-striatal tract with neurotrophin gene therapy. Key Words: Blood-brain barrier, liposomes, transferrin receptor, monoclonal antibody, targeting.

\section{INTRODUCTION}

Parkinson's disease (PD) affects nearly $1 \%$ of the U.S. population over 65 years and nearly 1 million individuals in the U.S. ${ }^{1}$ The neurodegneration of the nigral-striatal tract results in a loss of dopaminergic neurons in the substantia-nigra, a loss of tyrosine hydroxylase containing nerve endings in the striatum, and diminished striatal dopamine production causing abnormal motor behavior. ${ }^{2}$ Dopamine replacement therapy with dopamine is not possible in PD because this monoamine does not cross the brain capillary endothelial wall, which forms the blood-brain barrier (BBB) in vivo. However, the precursor to dopamine, L-dihydroxyphenylalanine (L-DOPA), does cross the BBB owing to transport via the BBB large neutral amino acid transporter, which is expressed by the LAT1 gene. ${ }^{3}$ After its transport across the BBB, L-DOPA is decarboxylated to dopamine by aromatic amino acid decarboxylase (AAAD). The rate-limiting step in cere-

Address correspondence and reprint requests to William M. Pardridge, M.D., Department of Medicine, UCLA Warren Hall 13-164, 900 Veteran Avenue, Los Angeles, CA 90024. E-mail: wpardridge@mednet.ucla.edu. bral production of dopamine is normally the conversion of tyrosine to L-DOPA via tyrosine hydroxylase (TH).

L-DOPA replacement therapy has been the mainstay of Parkinson's treatment for 40 years. However, L-DOPA therapy is not without complications. Owing to ubiquitous expression of both AAAD in brain and LAT1 at the $\mathrm{BBB}$, circulating L-DOPA is converted to dopamine throughout all parts of the brain including the striatum. Dopamine is an inhibitory neurotransmitter, and the ectopic production throughout the brain has side effects. An alternative approach to dopamine replacement therapy in PD is TH gene therapy, wherein an exogenous TH gene is expressed only in the circumscribed regions of the brain forming the dopaminergic nerve tracts.

\section{OVERVIEW OF GENE THERAPY IN PARKINSON'S DISEASE}

There are dual goals of gene therapy in PD: 1) replace striatal TH and 2) halt or even reverse the neurodegeneration of nigral-striatal neurons. The latter can be accomplished with local expression of neuroprotective neurotrophins such as glial-derived neurotrophic factor 
(GDNF). ${ }^{4}$ The current approach to gene therapy of PD, and gene therapy of brain disorders in general, is the combined use of craniotomy as a delivery system, and viral vectors as a gene expression system. The transcranial injection of viral gene therapy vectors is clearly effective, including primate models, and allows for the local production of therapeutic genes. ${ }^{4}$ The single injection into the human or animal brain of either adenovirus or herpes simplex virus results in inflammatory reaction leading to astrogliosis and demyelination, ${ }^{5,6}$ and more recent viral gene therapy approaches employ either adeno-associated virus (AAV) or retrovirus. AAV vectors generally need to be given at some repeat intervals, and $90 \%$ of the human population has a pre-existing immunity to $\mathrm{AAV} .{ }^{7}$ Both AAV and retrovirus permanently and randomly integrate into the host genome. ${ }^{8,9}$ Neither AAV nor retrovirus crosses the BBB. Therefore, it is necessary to administer the virus via craniotomy and an intracerebral injection. However, the most intense expression of the therapeutic gene is generally limited to the injection site, owing to limited diffusion of the virus within the brain. The treatment volume can be increased with convection-enhanced diffusion (CED). However, a recent study of CED in the primate brain shows an astrogliotic reaction over the entire region of the primate brain that is perfused during the CED procedure. ${ }^{10} \mathrm{Cur}-$ rent limitations of brain gene therapy approaches can be eliminated with the development of a transvascular delivery approach to gene therapy. However, this would require the formulation of plasmid DNA in such a way that the exogenous gene was able to cross the BBB and enter brain via the transvascular route after an intravenous injection. This is now possible with the use of a pegylated immunoliposomes that target genes across the BBB with receptor-specific molecular Trojan horses. ${ }^{11}$

\section{PEGYLATED IMMUNOLIPOSOMES-A NEW APPROACH TO TRANSVASCULAR GENE THERAPY OF THE BRAIN}

Exogenous genes incorporated in plasmid DNA can be widely distributed throughout the entire brain after an intravenous injection with the use of a new form of transvascular gene transfer technology that uses pegylated immunoliposomes, or PILs. The plasmid DNA is encapsulated in the interior of a $100-\mathrm{nm}$ liposome. ${ }^{12}$ The surface of the liposome is decorated with several thousand strands of 2000-Da polyethyleneglycol (PEG), and this pegylation process alters the surface of the liposome such that the liposome is not rapidly cleared by the reticulo-endothelial system after an intravenous administration. The pegylated liposome is relatively inert and does not cross the BBB. ${ }^{13}$ However, transvascular transport of the PIL can be induced by conjugating receptor specific monoclonal antibodies (mAbs) to the tips of
$1-2 \%$ of the PEG tails so that each 100-nm liposome is conjugated with approximately $50 \mathrm{mAb}$ molecules. ${ }^{12,13}$ A drawing of a PIL is shown in Figure 1A. An actual PIL is visualized with electron microscopy as shown in Figure 1B. In this study, a conjugate of $10 \mathrm{~nm}$ gold and a secondary antibody was attached to the surface of the PIL to demonstrate the relationship of the targeting $\mathrm{mAb}$ to the surface of the PIL. ${ }^{14}$ The size of a $10-\mathrm{nm}$ gold particle is approximately the size of the targeting $\mathrm{mAb}$, as depicted in Figure 1B. The plasmid DNA is encapsulated in the interior of the liposome, which renders the DNA insensitive to the ubiquitous exo- and endonucleases in the circulation. ${ }^{12}$

The PIL is to be contrasted with conventional cationic liposomes that are a mixture of anionic DNA and a cationic polymer. Cationic liposome/DNA complexes are unstable in blood, aggregate in a saline environment, and are more than $99 \%$ cleared by the pulmonary circulation after a single intravenous injection. ${ }^{15,16}$ Cationic liposomes do not distribute to the brain after an intravenous administration. ${ }^{17}$

PILs act as an artificial virus in that the PILs are approximately the same size as a virus, the DNA is contained inside the nanocontainer, and the surface of the nanocontainer has proteins that trigger uptake across membrane barriers. The targeting component of the PIL is a receptor-specific $\mathrm{mAb}$ that is conjugated to the tips of $1-2 \%$ of the PEG strands on the liposome surface. ${ }^{12}$ The transferrin receptor (TfR) or the insulin receptor are expressed at both the BBB and on neuronal cell membranes. Therefore, a PIL, targeted with a mAb to either the TfR or the insulin receptor, is able to undergo sequential receptor-mediated transcytosis across the BBB, followed by receptor-mediated endocytosis into neurons. ${ }^{18,19}$ The PIL rapidly enters the nuclear compartment after endocytosis into the cell, as demonstrated by confocal microscopy. ${ }^{20}$ In this study, the plasmid DNA was fluoresceinated with nick translation before encapsulation into PIL. The PIL was targeted to human U87 glioma cells using the murine 83-14 mAb to the human insulin receptor (HIR). The HIRmAb-targeted PIL was added to U87 cells and incubated for 3 or $24 \mathrm{~h}$, followed by fixation and confocal microscopy. As shown in Figure $1 \mathrm{C}$, the DNA is largely confined to the cytoplasmic compartment at $3 \mathrm{~h}$, although DNA is detected within intranuclear vesicular structures at $3 \mathrm{~h}$. By $24 \mathrm{~h}$, virtually all of the intracellular DNA is found in the nuclear compartment (FIG. 1C).

\section{Global expression of transgene in rhesus monkey brain}

The intravenous administration of PILs carrying an expression plasmid encoding bacterial $\beta$-galactosidase under the influence of the simian virus 40 (SV40) promoter to the adult rhesus monkey leads to global expres- 

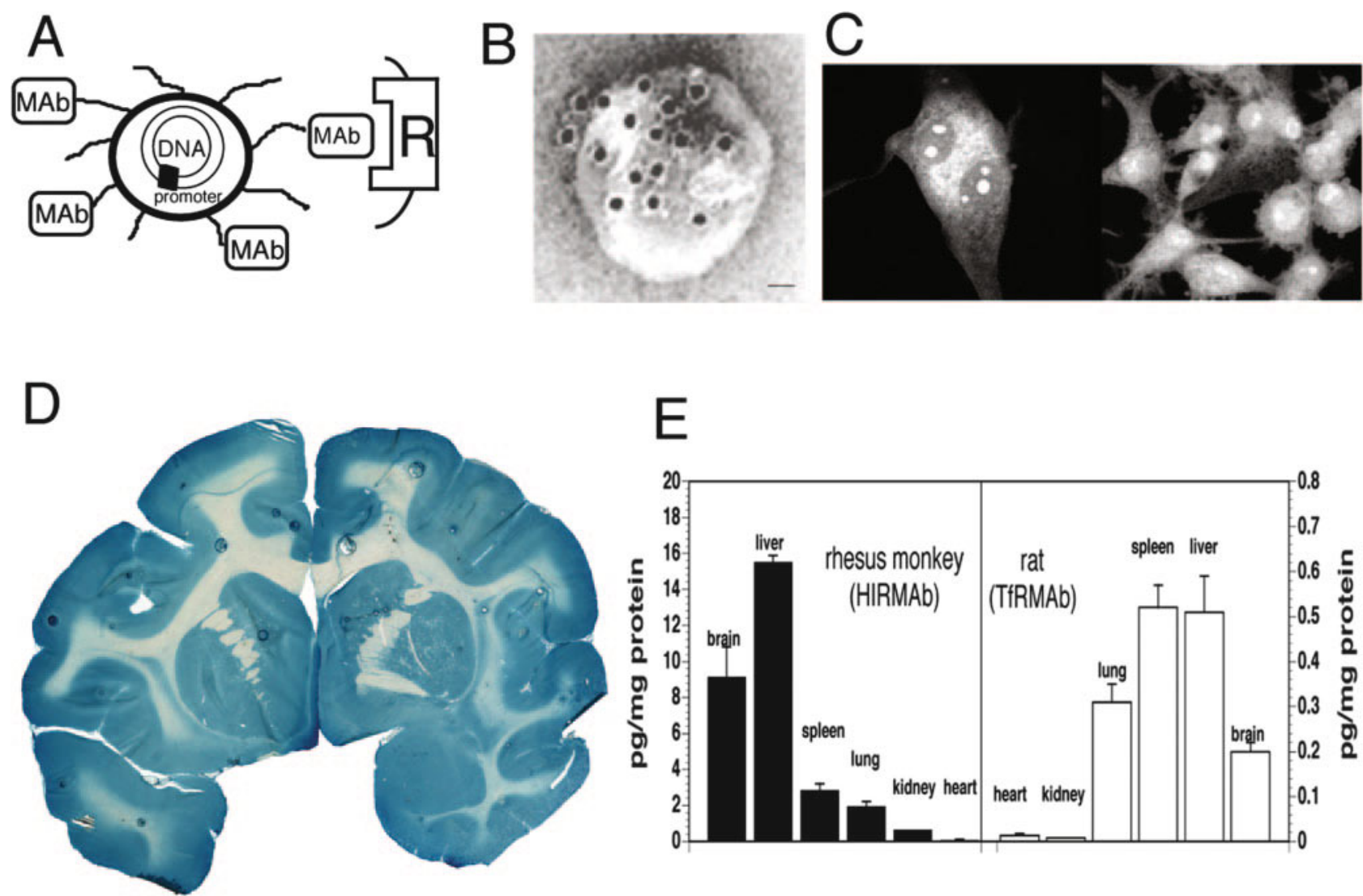

FIG. 1. A: Diagram of a super-coiled expression plasmid DNA encapsulated in an $85 \mathrm{~nm}$ pegylated PIL targeted to a cell membrane receptor $(\mathrm{R})$ with a receptor-specific, endocytosing $\mathrm{mAb}$. Tissue-specific expression of the plasmid can be controlled by the promoter inserted $5^{\prime}$ of the gene. Panels A and B are reproduced with permission from Zhang et al. Intravenous nonviral gene therapy causes normalization of striatal tyrosine hydroxylase and reversal of motor impairment in experimental parkinsonism. Hum Gene Ther 14:1-12. Copyright $\odot$ 2003, Mary Ann Leibert, Inc. All rights reserved. ${ }^{14}$ B: Transmission electron microscopy of a PIL. The mAb molecule tethered to the tips of the 2000-Da PEG is bound by a conjugate of $10 \mathrm{~nm}$ gold and a secondary antibody. The position of the gold particles shows the relationship of the PEG extended mAb and the liposome. Magnification bar $=20 \mathrm{~nm} \cdot{ }^{14} \mathrm{C}$ : Confocal microscopy of U87 human glioma cells after either a 3-h (left panel) or a 24-h (right panel) incubation of fluorescein conjugated clone 882 DNA (fluoro-DNA) encapsulated within HIRmAb-PILs. The inverted grayscale image is shown. There is primarily cytoplasmic accumulation of the fluoroDNA at $3 \mathrm{~h}$, whereas the fluoro-DNA is largely confined to the nuclear compartment at $24 \mathrm{~h}$. Fluoro-DNA entrapped within intranuclear vesicles is visible at both 3 and $24 \mathrm{~h}$. Panel $\mathrm{C}$ is reproduced with permission from Zhang et al. Receptor-mediated delivery of an antisense gene to human brain cancer cells. J Gene Med 4:183-194. Copyright $\odot 2002$, John Wiley \& Sons, Ltd. All rights reserved. ${ }^{20}$ D: $\beta$-Galactosidase histochemistry of brain removed $48 \mathrm{~h}$ after the intravenous injection of a $\beta$-galactosidase expression plasmid encapsulated in HIRmAb-PILs in the adult rhesus monkey. Panels D and E are reproduced with permission from Zhang et al. Global non-viral gene transfer to the primate brain following intravenous administration. Mol Ther 7:11-18. Copyright ${ }^{\odot} 2003$, Academic Press. All rights reserved. ${ }^{19} \mathrm{E}$ : Luciferase gene expression in the brain and other organs of the adult rhesus monkey (left panel) and adult rat (right panel) measured at $48 \mathrm{~h}$ after a single intravenous injection of the PIL carrying the plasmid DNA. Data are mean \pm SEM. The plasmid DNA encoding the luciferase gene used in either species is clone 790 , which is driven by the SV40 promoter. ${ }^{19}$ The PIL carrying the DNA was targeted to primate organs with an HIRmAb and to rat organs with a TfRmAb. ${ }^{19}$

sion of the trans-gene throughout the primate brain as demonstrated in Figure 1D. The PIL was targeted with a $\mathrm{mAb}$ to the HIR, and this mAb cross reacts with the Old World primate insulin receptor. ${ }^{21}$ There is widespread expression of the transgene throughout the primate brain with a greater enrichment in gray matter relative to white matter (FIG. 1D). Similar findings of global expression of a trans-gene throughout the entire brain after an intravenous injection of PILs has been demonstrated in mice using the rat $8 \mathrm{D} 3 \mathrm{mAb}$ to the murine $\mathrm{TfR},{ }^{18}$ and in rats using the murine $\mathrm{OX} 26 \mathrm{mAb}$ to the rat $\mathrm{TfR}^{22}$ The targeting $\mathrm{mAbs}$ are species specific, and the $8 \mathrm{D} 3 \mathrm{mAb}$ is not effective in rats, and the $83-14 \mathrm{HIRmAb}$ is effective in humans and Old World primates such as rhesus monkeys, but is not effective in New World primates such as squirrel monkeys, and is not effective in rodents. The insulin receptor normally serves to deliver its endogenous ligand, insulin, to the nuclear compartment, and therefore, the insulin receptor is an ideal conduit for gene delivery. ${ }^{23}$ Because of this nuclear targeting property of the insulin receptor, levels of gene expression in human cells or Old World primates can be 10- to 50-fold higher than comparable levels of gene expression in rodents, ${ }^{19,23}$ as demonstrated for the luciferase reporter gene (FIG. 1E). The luciferase expression plasmid was encapsulated in TfRmAb-targeted PILs and injected into 
TABLE 1. TH Activity in Cultured Rat RG2 Glioma Cells or Human U87 Glioma Cells after Delivery of either SV40 Promoter (clone 877) or GFAP Promoter (Clone 951) TH Expression Plasmid Encapsulated in mAb-Targeted PIL

\begin{tabular}{lccc}
\hline & & TH Activity (pmol-L-DOPA/h $\cdot \mathrm{mg}_{\mathrm{p}}$ ) & \\
\cline { 2 - 4 } Days & $\begin{array}{c}\text { Clone } 877 \text { in } \\
\text { rat RG2 cells }\end{array}$ & $\begin{array}{c}\text { Clone } 877 \text { in } \\
\text { human U87 cells }\end{array}$ & $\begin{array}{c}\text { Clone 951 in } \\
\text { human U87 cells }\end{array}$ \\
\hline 2 & $65 \pm 7$ & $214 \pm 14$ & $231 \pm 10$ \\
4 & $375 \pm 26$ & $1458 \pm 99$ & $1576 \pm 33$ \\
6 & $39 \pm 9$ & $177 \pm 10$ & $311 \pm 22$ \\
\hline
\end{tabular}

Mean \pm SE ( $n=3$ dishes per time point). PILs carrying either clone 877 or clone 951 are targeted to rat RG2 glioma cells with the TfRmAb and to human U87 glioma cells with the HIRmAb. ${ }^{14,25}$

adult rats, and was separately encapsulated in HIRmAbtargeted PILs and injected into adult rhesus monkeys. ${ }^{19}$ The animals were sacrificed $48 \mathrm{~h}$ after the intravenous injection for measurements of luciferase enzyme activity in brain and other organs. These studies show that luciferase expression is 50 -fold higher in the primate as compared with rat. In addition to brain, the luciferase transgene is expressed in peripheral tissues such as liver or spleen, that also express the TfR or insulin receptor. However, this ectopic expression of the exogenous gene in nonbrain organs can be eliminated with the use tissuespecific gene promoters, as demonstrated for $\beta$-galactosidase gene expression in mice ${ }^{18}$ or rhesus monkeys, ${ }^{24}$ and discussed below in the case of $\mathrm{TH}$ gene therapy studies in rats.

\section{TH GENE THERAPY OF EXPERIMENTAL PARKINSON'S DISEASE WITH PEGYLATED IMMUNOLIPOSOMES}

Experimental PD was produced in adult rats with the intracerebral injection of a neurotoxin, 6-hydroxydopamine. ${ }^{14,25}$ The toxin was injected in the medial forebrain bundle of one side of the rat brain under stereotaxic guidance. Three weeks later, animals were tested with apomorphine, which causes aberrant rotation behavior in those animals with a successful biochemical lesion of the nigral-striatal tract. Before treatment of these animals with TH gene therapy, it is first necessary to synthesize TH expression plasmids. Because one goal of this work was to localize $\mathrm{TH}$ gene expression in the brain, two different expression plasmids were produced. ${ }^{14,25}$ The first plasmid, designated clone 877, encodes for the rat TH cDNA under the influence of the widely read SV40 promoter. ${ }^{14}$ The second expression plasmid, designated clone $951,{ }^{25}$ is identical, except that the SV40 promoter is replaced with $2 \mathrm{~kb}$ of the $5^{\prime}$-flanking sequence (FS) of the human GFAP gene. The GFAP gene is expressed only in brain, and not in peripheral tissues. This was demonstrated in initial studies with a $\beta$-galactosidase reporter gene. When the $\beta$-galactosidase expression plasmid under the influence of the SV40 promoter was encapsulated in TfRmAb-targeted PILs and injected into rodents, the gene was expressed not only in brain, but TfR-rich peripheral organs such as liver or spleen. ${ }^{22}$ However, when the $\beta$-galactosidase expression plasmid was under the influence of the GFAP promoter, the transgene was expressed only in brain, and ectopic gene expression in peripheral tissues was eliminated. ${ }^{18}$

The biologic activity of clone 877 or clone 951 was initially evaluated in cell culture with either cultured RG2 rat glioma cells or cultured U87 human glioma cells. The TH gene is not expressed in cells unless there is local production of tetrahydrobiopterin, a critical $\mathrm{TH}$ cofactor. GTP-cylcohydrolase (GTPCH) is the rate-limiting enzyme in the pathway leading to the production of tetrahydrobiopterin, and cultured rat glioma cells ${ }^{26}$ and cancer cell lines ${ }^{27}$ produce the GTPCH enzyme, although glial cells in brain do not normally express the GTPCH gene. ${ }^{28}$ Both clone 877 and clone 951 produce TH enzyme activity in either cultured rat glioma cells or cultured human U87 glioma cells (Table 1). There is a 5to 8 -fold higher level of TH gene expression in human cells, which are targeted with the HIRmAb, as opposed to $\mathrm{TH}$ gene expression in rat glioma cells, which are targeted with the TfRmAb. As noted above in the discussion of Figure 1E, PILs targeted with the insulin receptor normally yield a much higher level of gene expression than that obtained with PILs targeted with the TfRmAb. ${ }^{19,23}$

The TfRmAb-targeted PILs carrying either clone 877 or clone 951 were injected intravenously into adult rats and $\mathrm{TH}$ enzyme activity was measured with a radioenzymatic assay at 3 days after a single intravenous injection in rats that had apomorphine-proven 6-hydroxydopamine lesions. The striatal TH was $98 \%$ depleted, as indicated by the very low TH level in the saline treated animals in the striatum ipsilateral to the 6-hydroxydopamine injection (Table 2). The control is the contralateral striatum, which shows a more than 50-fold higher level of TH enzyme activity in the same rat brain (Table 2). Both clone 877, the SV40 promoter driven plasmid, and clone 951, the GFAP promoter driven plasmid, were equally effective in restoring striatal TH enzyme activity in the ipsilateral striatum of the lesioned animals. ${ }^{14,25}$ 
TABLE 2. TH in Brain and Peripheral Organs in the Rat 3 Days after Intravenous Injection of Gene Therapy

\begin{tabular}{lccc}
\hline Organs & $\begin{array}{c}\text { Saline } \\
\left(\mathrm{pmol} / \mathrm{h} / \mathrm{mg}_{\mathrm{p}}\right)\end{array}$ & $\begin{array}{c}\text { TfRmAb-PIL/877 } \\
\left(\mathrm{pmol} / \mathrm{h} / \mathrm{mg}_{\mathrm{p}}\right)\end{array}$ & $\begin{array}{c}\text { TfRmAb-PIL/951 } \\
\left(\mathrm{pmol} / \mathrm{h} / \mathrm{mg}_{\mathrm{p}}\right)\end{array}$ \\
\hline Ipsilateral striatum & $128 \pm 27$ & $5177 \pm 446^{*}$ & $5536 \pm 395^{*}$ \\
Contralateral striatum & $6445 \pm 523$ & $5832 \pm 391$ & $5713 \pm 577$ \\
Ipsilateral cortex & $176 \pm 30$ & $132 \pm 16$ & $184 \pm 38$ \\
Contralateral cortex & $150 \pm 36$ & $150 \pm 24$ & $135 \pm 25$ \\
Heart & $29 \pm 3$ & $45 \pm 8$ & $31 \pm 3$ \\
Liver & $13 \pm 2$ & $130 \pm 28^{*}$ & $18 \pm 6$ \\
Lung & $42 \pm 13$ & $74 \pm 22$ & $30 \pm 6$ \\
Kidney & $24 \pm 2$ & $35 \pm 5$ & $31 \pm 8$ \\
\hline
\end{tabular}

$* p<0.01$ difference from saline group (ANOVA with Bonferroni correction; $\mathrm{n}=4$ rats per group). Rats were lesioned with intracerebral injections of 6-hydroxydopamine; 3 weeks after toxin injection the rats were tested for apomorphine-induced rotation behavior; those rats testing positively to apormorphine were selected for gene therapy, which was administered intravenously 4 weeks after toxin administration; all animals were euthanized 3 days after gene administration. Clones 877 and 951 are eukaryotic expression plasmids encoding the rat TH cDNA under the influence of either the widely expressed SV40 promoter, or the brain-specific GFAP promoter, respectively. ${ }^{25}$

Clone 877 also produced a 10 -fold increase in hepatic TH because the SV40 promoter is expressed in this peripheral tissue. However, clone 951 caused no change in hepatic TH enzyme activity, and there was no ectopic expression of the $\mathrm{TH}$ gene in any of the peripheral tissues examined (Table 2). Administration of the TH gene did not result in any change in cortical TH enzyme activity. This is because the GTPCH gene is not expressed in cortex ${ }^{29}$ and local production of the tetrahydrobiopterin cofactor is an obligatory requirement for local $\mathrm{TH}$ gene expression. The biochemical assays of TH enzyme activity were corroborated with immunocytochemistry and measurements of immunoreactive TH (FIG. 2). This study shows the results from six different rats, all of which had apomorphine proven 6-hydroxydopamine lesions on the right side of the brain. The three animals in panels A, B, and C of Figure 2 were treated with the TH gene encapsulated in PILs targeted with the TfRmAb. The three animals shown in D, E, and F of Figure 2 were treated with the TH gene encapsulated in PILs targeted with the mouse IgG2A isotype control, which had no receptor specificity. This immunocytochemical study shows complete normalization of striatal immunoreactive $\mathrm{TH}$ on the lesioned side with PIL gene therapy,
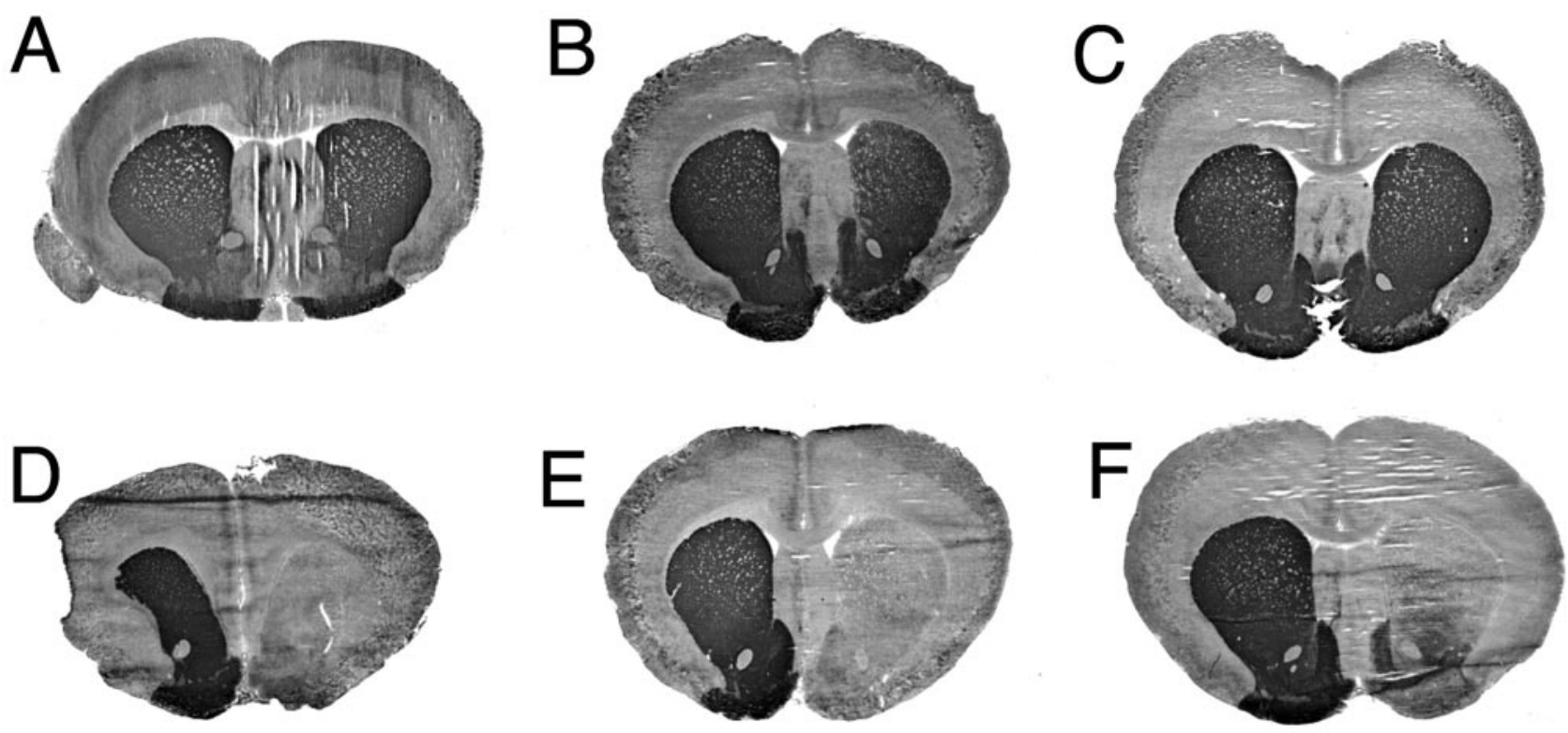

FIG. 2. Tyrosine hydroxylase immunocytochemistry of rat brain removed $72 \mathrm{~h}$ after a single intravenous injection of $10 \mu \mathrm{g}$ per rat of clone 951 plasmid DNA encapsulated in PIL targeted with either the TfRmAb (panels A-C) or with the mouse IgG2a isotype control (panels D-F). Coronal sections are shown for three different rats from each of the two treatment groups. Clone 951 is the TH expression plasmid under the influence of the human GFAP promoter. The 6-hydroxydopamine was injected in the medial forebrain bundle of the right hemisphere, which corresponds to right side of the figure. Sections are not counterstained. Reproduced with permission from Zhang et al. Normalization of striatal tyrosine hydroxylase and reversal of motor impairment in experimental parkonsinism with intravenous nonviral gene therapy and a brain-specific promotor. Hum Gene Ther 15:339-350. Copyright ${ }^{\circ}$ 2004, Mary Ann Liebert, Inc. All rights reserved. ${ }^{25}$ 
providing a receptor active targeting $\mathrm{mAb}$ is used. If an identical formulation is employed, except the TfRmAb targeting agent is replaced with a nontargeting agent, then no TH gene expression is observed. These results were corroborated by confocal microscopy using antibodies to TH, GFAP, the NeuN neuronal nuclear antigen, or the 200-kDa neurofilament protein (FIG. 3). The fibers in the striate body ipsilateral to the lesion were immunoreactive for $\mathrm{TH}$ after intravenous administration of the $\mathrm{TH}$ gene encapsulated in TfRmAb targeted PILs (FIG. $3 \mathrm{C}$ ), but there was no expression of immunoreactive $\mathrm{TH}$ in these fibers when the PIL was targeted with the mouse IgG isotype control (FIG. 3B). The expression of the immunoreactive $\mathrm{TH}$ in the striatum was confined to nerve endings as there was no colocalization of immunoreactive TH and astrocytic GFAP in the striate body of the gene therapy-treated animals (FIG. 3, G-I). Confocal microscopy of the substantia nigra showed production of immunoreactive TH in nigral neuron cell bodies after a TH gene therapy (FIG. 3, K and L). The normalization of striatal TH immunoreactive TH and striatal TH enzyme activity was correlated with the normalization of pharmacologic behavior in response to apomorphine. ${ }^{14,25}$ There was an $80 \%$ reduction in apomorphine induced rotation behavior in animals treated with intravenous $\mathrm{TH}$ gene therapy using PILs targeted with the TfRmAb (FIG. 4). In contrast, in those lesioned animals that were treated with the TH gene encapsulated in PILs targeted with the nonspecific mouse IgG isotype control, there was no affect on apomorphine induced rotation behavior (FIG. 4).

\section{Time-response and dose-response studies}

The persistence of TH gene expression in the striate body ipsilateral to the 6-hydroxydopamine lesion was determined with measurements of striatal TH enzyme activity at 3,6, and 9 days after a single intravenous injection of clone 877 plasmid DNA encapsulated in the TfRmAb-targeted PILs. ${ }^{14}$ These data show striatal TH enzyme activity peaks at 3 days and decreases $50 \%$ by 6 days and approximately $90 \%$ by 9 days after a single intravenous injection (FIG. 5A). A dose-response study was performed by measurement of TH enzyme activity in the striatum at 3 days after the intravenous injection of clone 877 plasmid DNA encapsulated in TfRmAb-targeted PILs at a dose of 1,5 , or $10 \mu \mathrm{g}$ plasmid DNA per rat. ${ }^{14}$ There was no increase in striatal TH after the $1 \mu \mathrm{g}$ DNA/rat dose; there was an intermediate TH response after the intravenous injection of the $5 \mu \mathrm{g} \mathrm{DNA} /$ rat dose, and there was complete normalization of striatal $\mathrm{TH}$ enzyme activity after the $10 \mu \mathrm{g}$ DNA/rat dose (FIG. 5B). A per rat dose of $10 \mu \mathrm{g}$ of the $6.0 \mathrm{~kb}$ clone 877 plasmid DNA delivers $1.2 \times 10^{9}$ plasmid molecules per gram of brain, as $0.07 \%$ of the injected PIL dose is delivered per gram of rat brain. ${ }^{14}$ Assuming $10^{8}$ cells per gram brain, the $10 \mu \mathrm{g} /$ rat dose delivers $\sim 12$ plasmid DNA molecules per brain cell. Conversely, only approximately one plasmid molecule per brain cell is delivered with $1 \mu \mathrm{g} / \mathrm{rat}$ dose. These observations suggest that there is a very high efficiency of cell transfection with the PIL gene transfer technology, and that the cellular delivery of only 5-10 plasmid DNA molecules per cell is required for a full pharmacologic response from the gene therapy. After delivery of the $\mathrm{TH}$ gene across the $\mathrm{BBB}$ in the region of the substantia nigra in brain, the gene is incorporated into the neuronal nuclear compartments of the substantia nigra where the gene is transcribed and the TH protein is translated from the TH mRNA produced from the exogenous plasmid. The TH enzyme may then be transported to the striatum via one of two mechanisms. First, there is intense neuronal sprouting from the substantia nigra to the striatum that follows the intracerebral injection of 6-hydroxydopamine, such that the density of dopaminergic terminals in the striatum is returned nearly to normal, albeit these nerve fibers do not produce $\mathrm{TH}$ in the absence of gene therapy. ${ }^{30,31}$ Second, intracerebral fluorogold injection studies have shown that approximately $30 \%$ of nigral striatal neurons are intact after intracerebral injection of 6-hydroxydopamine. ${ }^{32}$ Both GTPCH and the tetrahydrobiopterin cofactor levels in the striatum of the 6-hydroxydopamine-lesioned rat are still one third the concentrations in nonlesioned animal, ${ }^{33}$ owing to striatal inputs from monoaminergic regions outside the substantia nigra.

The PIL gene transfer technology enables adult transgenics in $24-48 \mathrm{~h}$ and gives a picture similar to that obtained with conventional transgenics technology that requires pronuclear injections of genes into embryos. Transgenic mice expressing the human $\mathrm{TH}$ gene produce no TH mRNA in the cortex of these animals, ${ }^{34}$ because there is no GTPCH gene expression or cofactor production in the cortex. Similarly, there is no change in $\mathrm{TH}$ gene expression in the cortex of adult rats administered the TH gene via the PIL gene transfer technology (Table 2). The level of TH gene expression is tightly regulated within the brain so that supraphysiological levels of $\mathrm{TH}$ are not generated in the brain. Despite a 50 -fold increase in TH mRNA in the substantia nigra of human TH transgenic mice, there is only a minor increase in TH protein in the striatum of these animals. ${ }^{34}$ This finding is consistent with the observations made with the PIL gene transfer technology, where the level of TH enzyme activity is restored to normal but not supranormal levels by intravenous TH gene therapy (Table 2).

\section{Brain gene expression driven by the GFAP promoter}

The confocal studies show that the TH gene is expressed in neurons when the transgene is under the influence of GFAP promoter (FIG. 3). Moreover, there is 

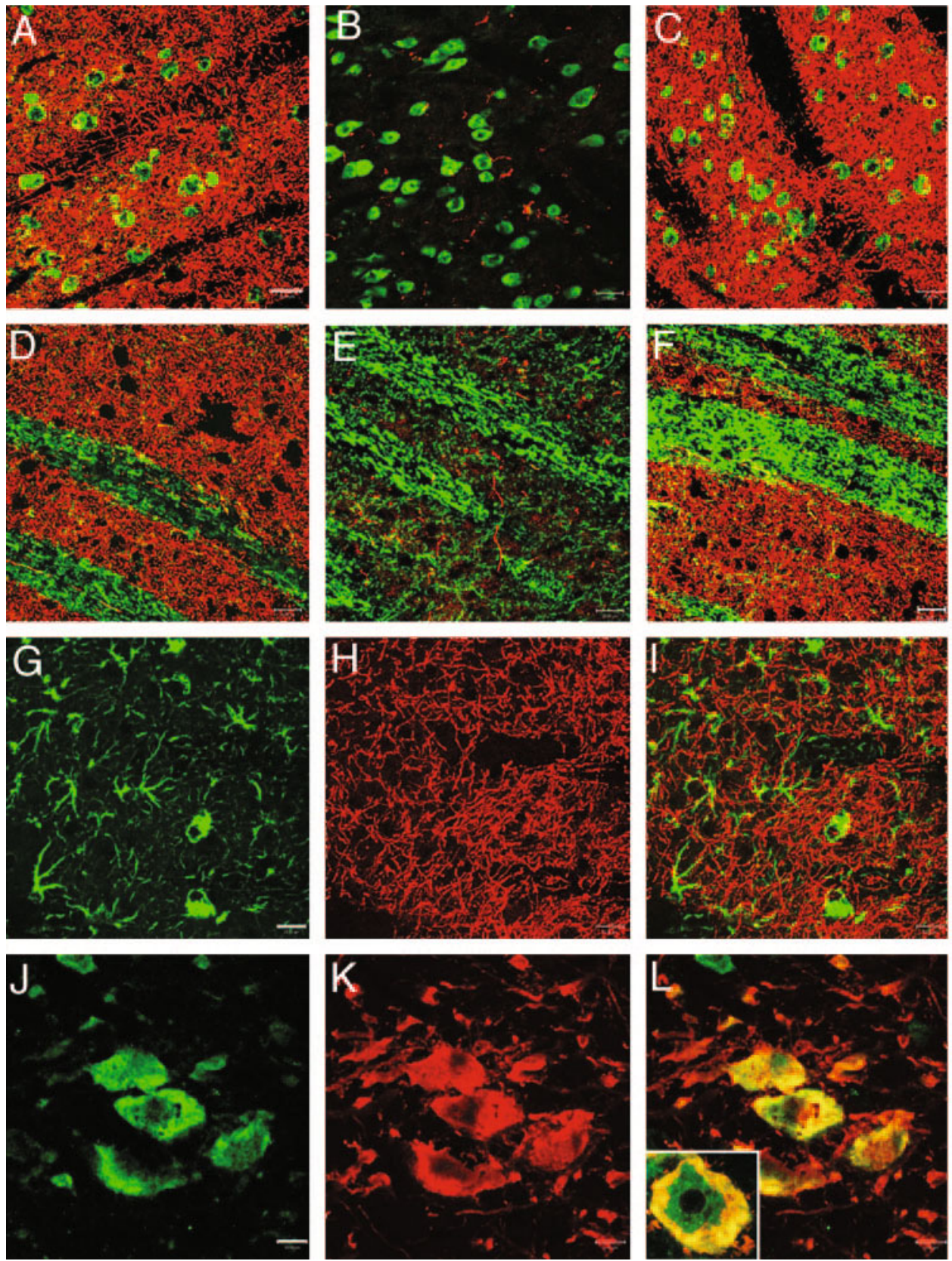

FIG. 3. Confocal microscopy of striatum and substantia nigra in 6-hydroxydopamine-lesioned rats sacrificed at 3 days after intravenous injection of clone 951 plasmid DNA encapsulated in PILs targeted either with mouse lgG2a (panels B and E) or with the TfRmAb (panels $\mathrm{A}, \mathrm{C}, \mathrm{D}, \mathrm{F}$, and $\mathrm{G}-\mathrm{L}$ ). Panels $\mathrm{A}$ and $\mathrm{D}$ are from the striatum contralateral to the lesion, and panels $\mathrm{B}, \mathrm{C}, \mathrm{E}, \mathrm{F}$, and $\mathrm{G}-\mathrm{I}$ are from the striatum ipsilateral to toxin injection. Panels $\mathrm{J}$ to $\mathrm{L}$ are from the substantia nigra ipsilateral to the lesion. Panels $\mathrm{A}-\mathrm{C}$ show striatum colabeled with a mouse monoclonal antibody to NeuN (green) and a rabbit polyclonal antibody to TH (red). Panels D-F show striatum colabeled with a mouse monoclonal antibody to the $200-\mathrm{kDa}$ neurofilament protein (green) and a rabbit polyclonal antibody to TH (red). The magnification bar in panel A is $20 \mu \mathrm{m}$. All images are three-dimensional projection views of multiple planar images. The yellow color is an artifact from the three-dimensional projection because there was no overlap observed in the single planar views. Panels $\mathrm{G}$ and $\mathrm{J}$ show immune staining (green channel) with monoclonal antibodies to GFAP and NeuN, respectively. Panels $\mathrm{H}$ and $\mathrm{K}$ show immune staining (red channel) with a rabbit polyclonal antibody to TH. The overlap image of TH and GFAP in striatum is shown in panel I; the overlap image of TH and NeuN in substantia nigra is shown in panel L. The inset of panel $L$ is a $100 \times$ oil immersion view of colabeling of TH (red), NeuN (green), and the overlap (yellow) in a neuron in the substantia nigra. The magnification bars in panels $\mathrm{G}$ and $\mathrm{J}$ are 20 and $10 \mu \mathrm{m}$, respectively. All images are three-dimensional projection views of multiple planar images. Reproduced with permission from Zhang et al. Normalization of striatal tyrosine hydroxylase and reversal of motor impairment in experimental parkinsonism with intravenous nonviral gene therapy and a brain-specific promotor. Hum Gene Ther 15:339-350. Copyright ${ }^{\circ}$ 2004, Mary Ann Liebert, Inc. All rights reserved. ${ }^{25}$ 

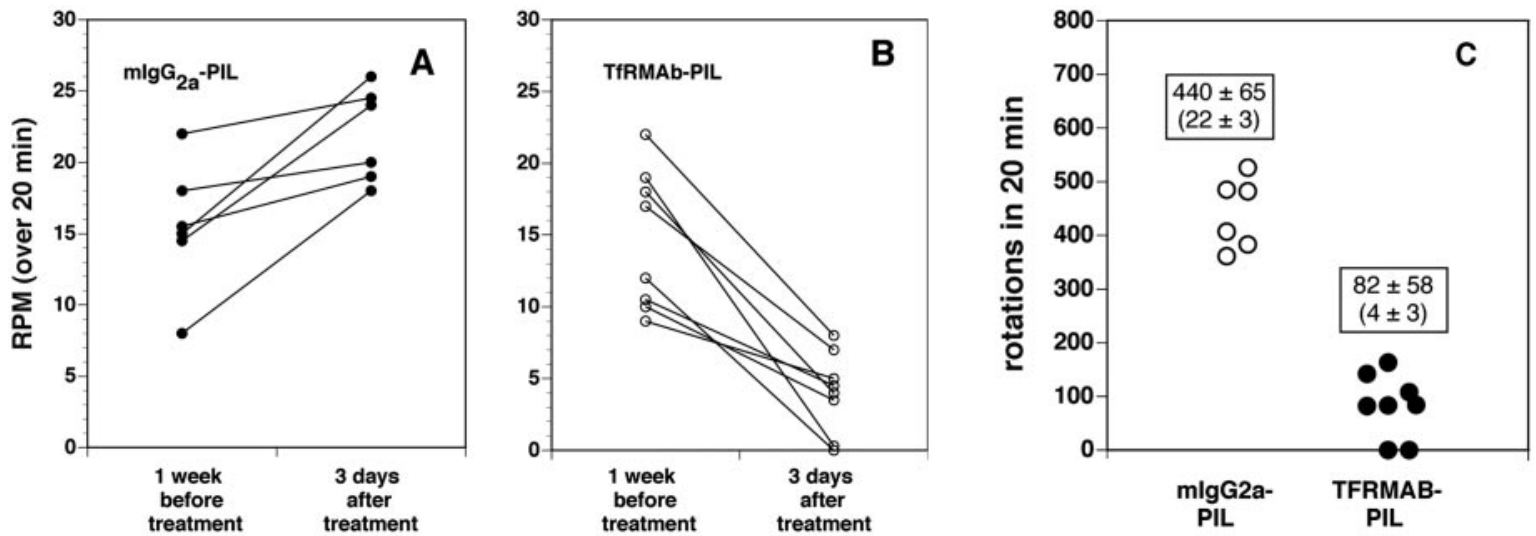

FIG. 4. A: Apomorphine-induced rotations per minute (RPM) over a 20-min period measured in individual rats at 1 week before treatment and at 3 days after a single intravenous injection of $10 \mu \mathrm{g}$ per rat of clone 951 plasmid DNA encapsulated in a PIL targeted with the mouse IgG2a isotype control antibody. B: Apomorphine-induced RPM over a 20 min period measured in individual rats at 1 week before treatment and at 3 days after a single intravenous injection of $10 \mu \mathrm{g}$ per rat of clone 951 plasmid DNA encapsulated in a PIL targeted with the TfRmAb. C: Comparison of the total rotations in the two groups at 3 days after treatment. The average RPM is $22 \pm 3$ and $4 \pm 3$ (mean \pm SD) in animals treated with the mlgG2a-PIL and the TfRmAb-PIL, respectively. The difference in rotation between the two groups is significant at the $p<0.005$ level. Reproduced with permission from Zhang et al. Normalization of striatal tyrosine hydroxylase and reversal of motor impairment in experimental parkonsinism with intravenous nonviral gene therapy and a brain-specific promotor. Hum Gene Ther 15:339-350. Copyright $\odot 2004$, Mary Ann Liebert, Inc. All rights reserved. ${ }^{25}$

no detectable expression of the TH gene in astrocytes based on confocal microscopy and colabeling with antibodies to TH and GFAP (FIG. 3I). This finding is consistent with the observation that astrocytes under normal conditions do not express the GTPCH gene. ${ }^{28}$ The intracerebral injection of $\mathrm{TH}$ expression plasmids under the influence of the GFAP promoter can lead to astrocyte gene expression in brain when the expression plasmid is mixed with cationic liposomes. ${ }^{35}$ However, cationic liposomes cause a brain injury reaction, ${ }^{36}$ and the GTPCH gene is expressed in reactive astrocytes. ${ }^{37}$ The finding of neuronal expression of the $\mathrm{TH}$ gene under the influence of the GFAP 5'-FS is consistent with earlier observations that the GFAP 5'-FS confers brain specificity of gene expression, but not astrocyte-specific gene expression. Astrocyte specific expression of the GFAP gene requires coordinated interactions between regulatory elements in both the 5'-FS and more distal parts of the gene, including the $3^{\prime}$-FS. ${ }^{38,39}$ Recent work in transgenic mouse models show that the $5^{\prime}$-FS of the GFAP gene enables widespread neuronal expression of transgene throughout the brain, ${ }^{40}$ and these findings are consistent with the
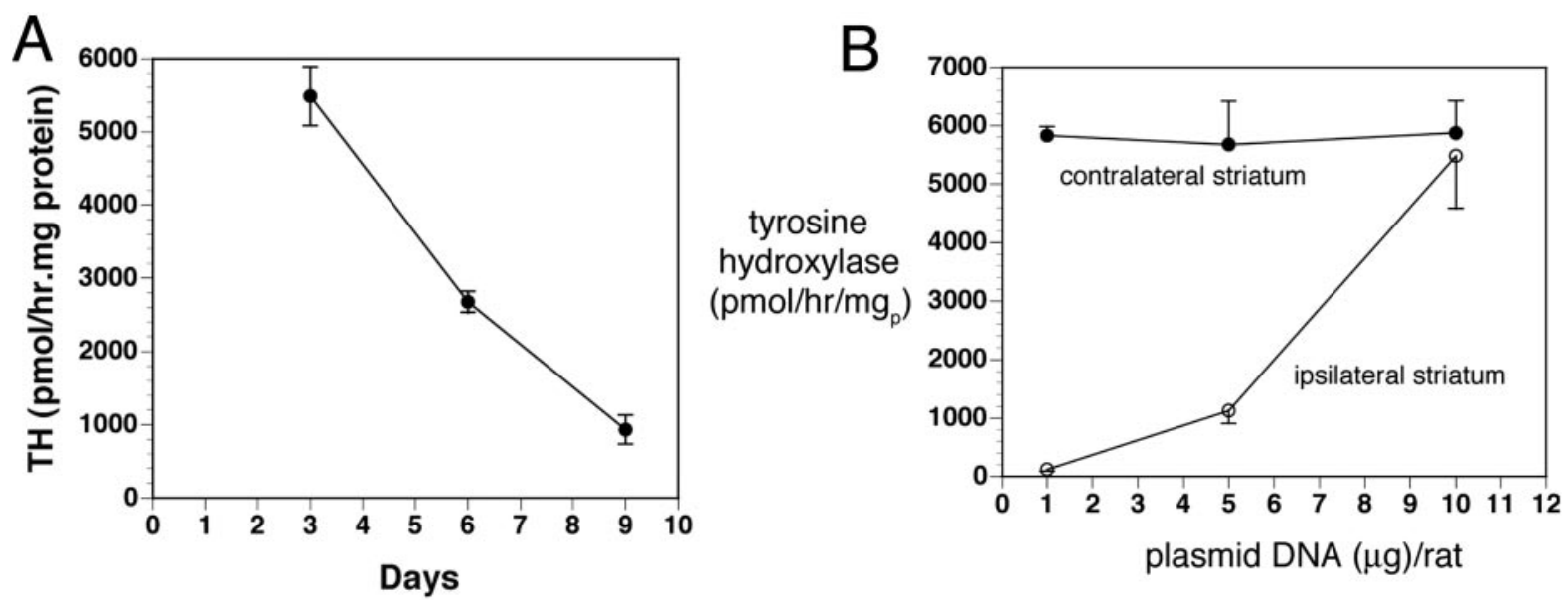

FIG. 5. A: The striatal TH activity ipsilateral to the 6-hydroxydopamine lesion is plotted versus time after a single intravenous injection of $10 \mu \mathrm{g} / \mathrm{rat}$ of clone 877 plasmid DNA encapsulated in the TfRmAb-PIL at day 0 . Data are mean $\pm \mathrm{SD}$ ( $\mathrm{n}=3$ rats per point). Clone 877 is the TH expression plasmid under the influence of the SV40 promoter. B: The striatal TH activity either ipsilateral or contralateral to the 6 -hydroxydopamine lesion is plotted versus the dose of clone 877 plasmid DNA encapsulated in the TfRmAb-PIL. Data are mean \pm SD ( $n=3$ rats per point). Striatal TH was measured at 3 days after the single intravenous administration of the DNA. Reproduced with permission from Zhang et al. Intravenous nonviral gene therapy causes normalization of striatal tyrosine hydroxylase and reversal of motor impairment in experimental parkinsonism. Hum Gene Ther 14:1-12. Copyright ${ }^{\odot}$ 2003, Mary Ann Liebert, Inc. All rights reserved. ${ }^{14}$ 
observations of other studies that neurons produce transacting factors that interact with the $5^{\prime}$-FS of the GFAP gene. $^{41}$

\section{FUTURE DIRECTIONS}

Gene expression in brain after administration of PILs is reversible and extrachromosomal. The plasmid DNA functions as an extrachromosomal episome, and persistence of expression of the transgene decays with time as the plasmid DNA is degraded. Southern blot studies show no chromosomal integration of the plasmid DNA. ${ }^{22}$ The reversible nature of episomal-based gene therapy is considered desirable and advantageous over viral delivery systems that cause permanent integration into the host genome. With episomal-based gene therapy, the risk of chromosomal integration is nil, and the gene is given chronically at repeat occasions as with any other therapeutic. The interval of repeat administration is determined by the persistence of the transgene expression, which is a function of the structural elements engineered within the plasmid DNA. If the plasmid DNA incorporates chromosomal derived elements, then the expression plasmid can attract transacting factors within brain cells, which stabilize the plasmid against degradation by DNase I, which may produce more prolonged periods of gene expression. Gene therapy needs to move from the sole reliance on cDNA-based forms of therapeutic genes, to chromosomal-derived genes that include both the coding region and important $5^{\prime}$ flanking sequence elements, and either intronic or $3^{\prime}$ flanking sequence elements that contribute to stability of gene expression within the cell.

PILs can be administered to humans chronically as the only immunogenic component of the formulation is the antibody and the immunogenicity of the antibody can be eliminated with genetic engineering and the use of chimeric or humanized antibodies. A genetically engineered chimeric HIRmAb has been produced and has identical affinity for the HIR as does the original murine 83-14 HIRmAb. ${ }^{42}$ PILs have been administered chronically by weekly intravenous administration to rats without any toxicologic effects and no inflammation within the brain. ${ }^{43}$ Multiple genes can be delivered to brain with the PIL gene transfer technology, and an ideal form of gene therapy of PD would be aimed at the dual goals of TH replacement gene therapy and neuroprotection gene therapy.

Acknowledgments: This work was supported by a grant from the U.S. Department of Defense Neurotoxin Exposure and Treatment Research Program.

\section{REFERENCES}

1. Shastry BS. Parkinson disease: etiology, pathogenesis and future of gene therapy. Neurosci Res 41:5-12, 2001.

2. Booij J, Bergmans P, Winogrodzka A, Speelman JD, Wolters EC. Imaging of dopamine transporters with [123I]FP-CIT SPECT does not suggest a significant effect of age on the symptomatic threshold of disease in Parkinson's disease. Synapse 39:101-108, 2001.

3. Boado RJ, Li JY, Nagaya M, Zhang C, Pardridge WM. Selective expression of the large neutral amino acid transporter at the bloodbrain barrier. Proc Natl Acad Sci USA 96:12079-12084, 1999.

4. Kordower JH, Emborg ME, Bloch J, Ma SY, Chu Y, Leventhal L, et al. Neurodegeneration prevented by lentiviral vector delivery of GDNF in primate models of Parkinson's disease. Science 290:767773, 2000.

5. Dewey RA, Morrissey G, Cowsill CM, Stone D, Bolognani F, Dodd NJ, et al. Chronic brain inflammation and persistent herpes simplex virus 1 thymidine kinase expression in survivors of syngeneic glioma treated by adenovirus-mediated gene therapy: implications for clinical trials. Nat Med 5:1256-1263, 1999.

6. McMenamin MM, Byrnes AP, Charlton HM, Coffin RS, Latchman DS, Wood MJ. A $\gamma 34.5$ mutant of herpes simplex 1 causes severe inflammation in the brain. Neuroscience 83:1225-1237, 1998.

7. Chirmule N, Propert K, Magosin S, Qian Y, Qian R, Wilson $\mathrm{J}$. Immune responses to adenovirus and adeno-associated virus in humans. Gene Ther 6:1574-1583, 1999.

8. Miller DG, Rutledge EA, Russell DW. Chromosomal effects of adeno-associated virus vector integration. Nat Genet 30:147-148, 2002.

9. Laufs S, Gentner B, Nagy KZ, Jauch A, Benner A, Naundorf S, et al. Retroviral vector integration occurs in preferred genomic targets of human bone marrow-repopulating cells. Blood 101:21912198, 2003.

10. Ai Y, Markesbery W, Zhang Z, Grondin R, Elseberry D, Gerhardt GA, et al. Intraputamenal infusion of GDNF in aged rhesus monkeys: distribution and dopaminergic effects. J Comp Neurol 461: 250-261, 2003.

11. Pardridge WM. Drug and gene targeting to the brain with molecular Trojan horses. Nat Rev Drug Discov 1:131-139, 2002.

12. Shi N, Pardridge WM. Non-invasive gene targeting to the brain. Proc Natl Acad Sci USA 97:7567-7572, 2000.

13. Huwyler J, Wu D, Pardridge WM. Brain drug delivery of small molecules using immunoliposomes. Proc Natl Acad Sci USA 93: 14164-14169, 1996.

14. Zhang Y, Calon F, Zhu C, Boado RJ, Pardridge WM. Intravenous nonviral gene therapy causes normalization of striatal tyrosine hydroxylase and reversal of motor impairment in experimental parkinsonism. Hum Gene Ther 14:1-12, 2003.

15. Plank C, Tang MX, Wolfe AR, Szoka FC Jr. Branched cationic peptides for gene delivery: role of type and number of cationic residues in formation and in vitro activity of DNA polyplexes. Hum Gene Ther 10:319-332, 1999.

16. Hong K, Zheng W, Baker A, Papahadjopoulos D. Stabilization of cationic liposome-plasmid DNA complexes by polyamines and poly(ethylene glycol)-phospholipid conjugates for efficient in vivo gene delivery. FEBS Lett 400:233-237, 1997.

17. Osaka G, Carey K, Cuthbertson A, Godowski P, Patapoff T, Ryan A, et al. Pharmacokinetics, tissue distribution, and expression efficiency of plasmid [33P]DNA following intravenous administration of DNA/cationic lipid complexes in mice: use of a novel radionuclide approach. J Pharm Sci 85:612-618, 1996.

18. Shi N, Zhang Y, Zhu C, Boado RJ, Pardridge WM. Brain-specific expression of an exogenous gene after i.v. administration. Proc Natl Acad Sci USA 98:12754-12759, 2001.

19. Zhang Y, Schlachetzki F, Pardridge WM. Global non-viral gene transfer to the primate brain following intravenous administration. Mol Ther 7:11-18, 2003.

20. Zhang Y, Jeong Lee H, Boado RJ, Pardridge WM. Receptormediated delivery of an antisense gene to human brain cancer cells. J Gene Med 4:183-194, 2002.

21. Pardridge WM, Kang YS, Buciak JL, Yang J. Human insulin receptor monoclonal antibody undergoes high affinity binding to human brain capillaries in vitro and rapid transcytosis through the blood-brain barrier in vivo in the primate. Pharm Res 12:807-816, 1995.

22. Shi N, Boado RJ, Pardridge WM. Receptor-mediated gene targeting to tissues in vivo following intravenous administration of pegylated immunoliposomes. Pharm Res 18:1091-1095, 2001.

23. Zhang Y, Boado RJ, Pardridge WM. Marked enhancement in gene 
expression by targeting the human insulin receptor. J Gene Med 5:157-163, 2003.

24. Zhang Y, Schlachetzki F, Li JY, Boado RJ, Pardridge WM. Organspecific gene expression in the rhesus monkey eye following intravenous non-viral gene transfer. Mol Vis 9:465-472, 2003.

25. Zhang Y, Schlachetzki F, Zhang YF, Boado RJ, Pardridge WM. Normalization of striatal tyrosine hydroxylase and reversal of motor impairment in experimental parkinsonism with intravenous nonviral gene therapy and a brain-specific promoter. Hum Gene Ther 15:339-350, 2004.

26. Vann LR, Payne SG, Edsall LC, Twitty S, Spiegel S, Milstien S. Involvement of sphingosine kinase in TNF- $\alpha$-stimulated tetrahydrobiopterin biosynthesis in C6 glioma cells. J Biol Chem 277: 12649-12656, 2002.

27. Nussler AK, Liu ZZ, Hatakeyama K, Geller DA, Billiar TR, Morris SM Jr. A cohort of supporting metabolic enzymes is coinduced with nitric oxide synthase in human tumor cell lines. Cancer Lett 103:79-84, 1996.

28. Nagatsu I, Ichinose H, Sakai M, Titani K, Suzuki M, Nagatsu T. Immunocytochemical localization of GTP cyclohydrolase I in the brain, adrenal gland, and liver of mice. J Neural Transm Gen Sect 102:175-188, 1995.

29. Shimoji M, Hirayama K, Hyland K, Kapatos G. GTP cyclohydrolase I gene expression in the brains of male and female hph-1 mice. J Neurochem 72:757-764, 1999.

30. Parish CL, Finkelstein DI, Tripanichkul W, Satoskar AR, Drago J, Horne MK. The role of interleukin-1, interleukin-6, and glia in inducing growth of neuronal terminal arbors in mice. $J$ Neurosci 22:8034-8041, 2002.

31. Stanic D, Finkelstein DI, Bourke DW, Drago J, Horne MK. Timecourse of striatal re-innervation following lesions of dopaminergic SNpc neurons of the rat. Eur J Neurosci 18:1175-1188, 2003.

32. Kozlowski DA, Connor B, Tillerson JL, Schallert T, Bohn MC. Delivery of a GDNF gene into the substantia nigra after a progressive 6-OHDA lesion maintains functional nigrostriatal connections. Exp Neurol 166:1-15, 2000.
33. Levine RA, Miller LP, Lovenberg W. Tetrahydrobiopterin in striatum: localization in dopamine nerve terminals and role in catecholamine synthesis. Science 214:919-921, 1981.

34. Kaneda N, Sasaoka T, Kobayashi K, Kiuchi K, Nagatsu I, Kurosawa Y, et al. Tissue-specific and high-level expression of the human tyrosine hydroxylase gene in transgenic mice. Neuron 6:583-594, 1991.

35. Segovia J, Vergara P, Brenner M. Astrocyte-specific expression of tyrosine hydroxylase after intracerebral gene transfer induces behavioral recovery in experimental parkinsonism. Gene Ther 5:1650-1655, 1998.

36. Bell H, Kimber WL, Li M, Whittle IR. Liposomal transfection efficiency and toxicity on glioma cell lines: in vitro and in vivo studies. Neuroreport 9:793-798, 1998.

37. Foster JA, Christopherson PL, Levine RA. GTP cyclohydrolase I induction in striatal astrocytes following intrastriatal kainic acid lesion. J Chem Neuroanat 24:173-179, 2002.

38. Kaneko R, Sueoka N. Tissue-specific versus cell type-specific expression of the glial fibrillary acidic protein. Proc Natl Acad Sci USA 90:4698-4702, 1993.

39. Galou M, Pournin S, Ensergueix D, Ridet JL, Tchelingerian JL, Lossouarn L, et al. Normal and pathological expression of GFAP promoter elements in transgenic mice. Glia 12:281-293, 1994.

40. Zhuo L, Theis M, Alvarez-Maya I, Brenner M, Willecke K, Messing A. hGFAP-cre transgenic mice for manipulation of glial and neuronal function in vivo. Genesis 31:85-94, 2001.

41. Gomes FC, Garcia-Abreu J, Galou M, Paulin D, Moura Neto V. Neurons induce GFAP gene promoter of cultured astrocytes from transgenic mice. Glia 26:97-108, 1999.

42. Coloma MJ, Lee HJ, Kurihara A, Landaw EM, Boado RJ, Morrison SL, et al. Transport across the primate blood-brain barrier of a genetically engineered chimeric monoclonal antibody to the human insulin receptor. Pharm Res 17:266-274, 2000.

43. Zhang YF, Boado RJ, Pardridge WM. Absence of toxicity of chronic weekly intravenous gene therapy with pegylated immunoliposomes. Pharm Res 20:1779-1785, 2003.

\section{ASENT Conflict of Interest Statement}

The American Society for Experimental NeuroTherapeutics (ASENT) comprises individuals from academia, industry, government, and the advocacy community. The mission of ASENT is to advance treatments for individuals at risk for or affected by disorders of the nervous system. Because ASENT receives financial contributions from industry and organizations in support of its programs, including publications and the annual scientific meeting, such financial relationships need to be fully disclosed. In order to ensure the integrity of its publications, including the journal NeuroRx ${ }^{\circledR}$, an editorial board was established to review the content of ASENT publications. In addition, ASENT has a Publications Oversight Committee to provide further review of real or potential conflicts of interest. All authors of ASENT publications are required to disclose any personal financial relationships with industry or organizations that may influence the content of their authored publication. Such disclosures are reported at the time of publication. 